Draft version: October 12, 2020.

This is a preprint of an Open Access article published in the British Journal of Psychology Coll-Martín, T., Carretero-Dios, H., \& Lupiáñez, J. (2021). Attentional networks, vigilance, and distraction as a function of attention-deficit/hyperactivity disorder symptoms in an adult community sample. British Journal of Psychology. Advance online publication. https://doi.org/10.1111/bjop.12513

\title{
Attentional Networks, Vigilance, and Distraction as a Function of ADHD Symptoms
}

\author{
Tao Coll-Martín ${ }^{1,2}$, Hugo Carretero-Dios ${ }^{1,2}$, and Juan Lupiáñez ${ }^{1,3}$ \\ ${ }^{1}$ Mind, Brain, and Behavior Research Center (CIMCYC), University of Granada \\ ${ }^{2}$ Department of Behavioral Sciences Methodology, University of Granada \\ ${ }^{3}$ Department of Experimental Psychology, University of Granada
}

\begin{abstract}
Author Note
Tao Coll-Martín (iDhttps://orcid.org/0000-0002-0591-4018

Hugo Carretero-Dios (Dhttps://orcid.org/0000-0001-8822-3791

Juan Lupiáñez (Dhttps://orcid.org/0000-0001-6157-9894

Data and material are publicly available in Coll-Martín et al. (2020; https://osf.io/k8jdm/). We have no potential conflict of interests to disclose. Our work was supported by a predoctoral fellowship (FPU17/06169) awarded to Tao Coll-Martín from the Spanish Ministry of Education, Culture, and Sport; a research project grant (PSI2016-79812-P) awarded to Hugo Carretero-Dios from the Spanish Ministry of Economy, Industry, and
\end{abstract}


Competitiveness; and a research project grant (PSI2017-84926-P) awarded to Juan Lupiáñez from the Spanish Ministry of Economy, Industry, and Competitiveness. The funders had no role in any stage of the development and publication of this work. We thank Sophie Forster for her generous availability and valuable intellectual inputs, Fernando Luna for his kind willingness to help with the reliability analysis, and Mateu Servera for his enthusiastic help with the instrument selection process.

Correspondence concerning this article should be addressed to Tao Coll Martín, Departamento de Metodología de las Ciencias del Comportamiento, Facultad de Psicología, Universidad de Granada, Campus Universitario de Cartuja s/n, 18071 Granada, Spain. Email: tcoll@ugr.es 


\begin{abstract}
Attentional difficulties are a core axis in attention-deficit/hyperactivity disorder (ADHD). However, establishing a consistent and detailed pattern of these neurocognitive alterations has not been an easy endeavor. The present study aimed at thoroughly characterizing three key attentional domains, namely, the three attentional networks (alerting, orienting, and executive attention), two components of vigilance (executive and arousal vigilance), and distraction. To do so, we modified a single, fine-grained task (the ANTI-Vea) by adding irrelevant distractors. One hundred and twenty undergraduates completed three questionnaires of ADHD symptoms in childhood and adulthood and performed the ANTI-Vea. Despite the low reliability of some ANTI-Vea indexes, the task worked successfully. While ADHD symptoms in childhood were related to alerting network and arousal vigilance, ADHD in adulthood were linked to executive vigilance. No association between ADHD symptoms and executive attention and distraction was found. In general, our hypotheses about the relationships between ADHD symptoms and attentional processes were supported only partially at most. We discuss our findings according to ADHD theories and attention measurement.

Keywords: attention-deficit/hyperactivity disorder, attentional networks, vigilance, distraction, measurement
\end{abstract}




\section{Attentional Networks, Vigilance, and Distraction as a Function of ADHD Symptoms}

Attention-deficit/hyperactivity disorder (ADHD) is a neurodevelopmental condition characterized by a persistent pattern of inattention and hyperactivity-impulsivity that is age inappropriate, manifests in two or more contexts, and interferes with social, academic, or occupational functioning (American Psychiatric Association [APA], 2013). Prevalence in childhood is estimated to be about $5 \%$, and the disorder frequently persists into adulthood (Faraone et al., 2006; Polanczyk et al., 2007; Simon et al., 2009). Across the lifespan, ADHD is a risk factor for several negative outcomes, including educational underachievement, difficulties with employment, and criminality (Faraone et al., 2015; Fletcher, 2014; Loe \& Feldman, 2007). Against this backdrop, both pharmacological (Cortese, 2020) and nonpharmacological (Evans et al., 2018) interventions in ADHD are making some progress to deal with ADHD-related symptoms and impairments. In this vein, understanding the neurocognitive mechanisms underlying ADHD symptoms is crucial to enhance the approach to the disorder via translational science (Castellanos \& Tannock, 2002; Luo et al., 2019; Sonuga-Barke \& Halperin, 2010).

Although inattention is one of its core symptoms, identifying attentional deficits in ADHD through cognitive tasks has not been an easy endeavor (Huang-Pollock \& Nigg, 2003; Huang-Pollock et al., 2005; Wilding, 2005). Research of attentional functioning in ADHD is grounded on theoretical frameworks that consider the distinct aspects of attention along with their neurobiological subtracts (Booth et al., 2007; Bush, 2010). Different theories have emphasized different aspects of attention, giving rise to a diversity of attentional phenomena that have even led some authors to question the very existence of attention as a consistent phenomenon (Hommel, et al, 2019). Alternatively, the three attentional networks model by Posner and colleagues (Petersen \& Posner, 2012; Posner \& Petersen, 1990) tries to solve this 
problem by considering the attentional system as three independent, albeit interactive, networks, each one implementing a different attentional function. First, the alerting network regulates the level of arousal and activation for both momentary readiness to imminent events (phasic alertness) and sustained performance over long time periods (tonic alertness or vigilance). This network involves noradrenergic innervations from the locus coeruleus towards frontal and parietal lobes of the right hemisphere. The second subsystem is the orienting network, responsible for prioritizing sensory inputs by selecting a modality or spatial location or object. It comprises cortical regions such as parietal cortices and frontal eye fields, and the subcortical structures of pulvinar nuclei and superior colliculi. Finally, the executive network is in charge of monitoring performance and prioritizing goal-oriented responses in conflictive situations. This third subsystem includes the anterior cingulate and prefrontal regions.

Several tasks have been developed to simultaneously measure these three components of attention, the most common being the Attention Network Test (ANT; Fan et al., 2002). This computerized task and other variants like the ANTI (Attention Network Test for the interaction; Callejas et al., 2004) presents a sequence of visual stimuli that combines a spatial cueing (Posner, 1980) and warning signal task with a flanker paradigm (Eriksen \& Eriksen, 1974). Subtractions of reaction times (RTs) between the different task conditions allow to obtain an efficiency index for each network. For example, in the ANTI, participants are required to determine in each trial whether a central arrow points to the left or right. The comparison between conflict (i.e., incongruent trials, with flanker pointing to the opposite direction as the target) and non-conflict conditions (i.e., congruent trials, with flankers pointing to the same direction as the target) provide the congruency effect, which is an index of executive attention. Interestingly, the target may or may not be preceded by an auditory noninformative warning cue and by a spatial cue 
(i.e., indicating one of the two possible target locations), which serves to calculate the alerting and orienting effect, respectively. In contrast to the ANT, the use of a different cue for measuring alertness and orienting in the ANTI allows also to measure the interaction between the three attentional networks.

Extensive research has used the ANT/ANTI or some of its variants to analyze the attentional networks in ADHD. A recent meta-analysis including the ANT and the ANT child version (Rueda et al., 2004) compared 491 ADHD children with 402 typical developing controls in nine studies (Arora et al., 2020). They found the functioning of the alerting and executive networks - but not orienting — to be impaired in ADHD. Moreover, Mullane et al. (2011) reported similar group differences using the ANTI. These results support Berger and Posner's (2000) original predictions regarding attentional networks in ADHD. In the same vein, impaired alerting and executive processes fall in line with energetic (Sergeant, 2000, 2005) and executive (Barkley, 1997) accounts of ADHD (Martella et al., 2020), respectively.

Notwithstanding the numerous studies using the ANT as a tool to characterize the attentional profile of ADHD, some concerns with this literature motivated our work. First, compared to children, the amount of research on ADHD adults and the ANT is somehow limited (Vázquez-Marrufo, et al., 2019). Moreover, this body of research offers mixed evidence about ADHD deficits in alerting and executive networks (Oberlin et al., 2005; Lampe et al., 2007; Freire-Bueno et al., 2015; Hasler et al., 2016), with those studies of greater statistical power failing to find differences between ADHD and controls individuals (e.g., Lundervold et al., 2011). Thus, the functioning of the attentional networks in relation to adult ADHD remains unclear. 
Secondly, as exposed above, research exploring the role of ADHD on attentional networks has essentially consisted in case-control studies comparing individuals with diagnosed ADHD to a community or nonclinical control group. This approach may be highly useful for some applied or clinical purposes. However, when it comes to research on the nature of ADHD, the study design could also consider some insights from the current bio-psycho-social perspective of the disorder (Engel, 1977; Richards, 2013; Singh, 2008; Sonuga-Barke, 2013, 2019). This model deems impairment derived from ADHD syndrome — one of the diagnostic criteria — not as inherent to symptoms, but rather as dependent on demands of the social context (Sonuga-Barke, 2013, 2019; Sonuga-Barke \& Fearon, 2019). Therefore, focusing exclusively on ADHD symptoms, rather than ADHD diagnosis (i.e., symptoms plus impairment), would provide a more direct connection to the neurocognitive processes underlying the core syndrome of the disorder. Furthermore, ADHD is now best understood as the extreme of a continuous dimension distributed throughout the population (Posner et al., 2020; Sonuga-Barke, 2013; Thapar, 2018). This is consistently supported not only at the level of symptoms (Haslam et al., 2006; Marcus \& Barry, 2011) but also in terms of their neurocognitive correlates (Fair et al., 2012). Overall, this notion of ADHD justifies the importance of studying the natural association between neurocognitive performance and ADHD symptoms in community samples. The two remaining issues concern the role of vigilance and distraction in the ANT/ANTI as well as in the ADHD literature. The next two sections will address each of them.

\section{Measuring Vigilance in ADHD: A Novel ANT Version}

Vigilance, understood as the attentional capacity to maintain performance over time, is one of the most widely studied phenomena in the ADHD literature (Huang-Pollock et al., 2012; Schoechlin \& Engel, 2005; Willcutt et al., 2005). The variety of terms and measures linked to 
vigilance have led some researchers to deem it as a multicomponent concept (Langner \& Eickhoff, 2013; Sturm et al., 1999; Luna et al., 2018).

On the one hand, vigilance tasks often consist in detecting an infrequent target among non-target stimuli (e.g., Continuous Performance Test [CPT], Rosvold et al., 1956; Conners' CPT, Conners, 2000; Test of Variables of Attention [TOVA], Greenberg \& Waldman, 1993). These tasks are forms of the CPT paradigm, which demands stimulus discrimination and response selection, suggesting executive aspects of vigilance to be involved (Luna et al., 2018). Despite variability among studies, substantial research has shown that both ADHD children (Huang-Pollock et al., 2012) and adults (Advokat et al., 2007; Barkley \& Murphy, 2011; Nikolas et al., 2019; Salomone et al, 2020; Riccio \& Reynolds, 2001) exhibit worse performance in numerous CPT indexes (i.e., RT mean and variability, hits, false alarms, and $d^{\prime}$ ). However, most studies in this literature only compare overall performance, but not the vigilance decrement over time (i.e., group-by-time interaction), despite this latter being considered the defining feature of vigilance (Esterman \& Rothlein, 2019; Huang-Pollock et al., 2012; Tucha et al., 2017). Indeed, research examining such change over time has often failed to demonstrate a greater vigilance decline in ADHD individuals (Cohen \& Shapiro, 2007; Epstein et al., 1998, 2001; Johnson et al., 2001; Solanto et al., 2004; Tucha, 2009). Only a few studies found that over time ADHD participants, compared to controls, displayed higher variability (Marchetta et al., 2008; Weyandt et al., 2017) and false alarms (Tucha et al., 2017), and lower reaction time (Weyandt et al., 2017) and hits (Gmehlin et al., 2016).

Alternatively, vigilance has been operationalized as reactivity to the environment, reflecting tonic arousal levels (Luna et al., 2018; Oken et al., 2006). These tasks involve keeping fast reactions to stimuli without exerting much control (i.e., without the consideration of 
alternative response options; see, e.g., the Psychomotor Vigilance Test, Dignes \& Powell, 1985). When these tasks are extremely short ( $\leq 20$ trials) no differences between ADHD and controls have been found (Tucha et al., 2006, 2008, 2009). Nonetheless, as tasks are longer, there is some evidence pointing that both children and adults with ADHD show slower RT and higher variability of response (Mary et al., 2015; Tucha et al., 2017). Similar to CPT, only a few studies have measured performance over time for this type of vigilance. They have found ADHD adults to exhibit a greater increase in variability — in terms of standard deviation or lapses - , but not in mean RT (Gmehlin et al., 2016; Tucha et al., 2017).

Although some efforts have been made to obtain measures of vigilance from the ANT in the ADHD literature (e.g., Adólfsdóttir et al., 2008; Bueno et al., 2015; Lundervold et al., 2011), neither this task nor the ANTI may provide a direct measure of such construct (Roca et al., 2011). Grounded on the aforementioned distinction between both concepts of vigilance, a novel version of the ANT has been developed: the ANT for Interactions and Vigilance-executive and arousal components (ANTI-Vea; Luna et al., 2018). Besides the three attentional networks and their interaction, the ANTI-Vea allows to measure two independent aspects of vigilance. To assess executive vigilance (EV), the flanker task is embedded in a CPT structure wherein in a few trials the target is presented largely displaced vertically from its central position, for participants to detect it by pressing a different response key. For its part, arousal vigilance (AV) is measured with a salient stimulus (i.e., a red down counter) that participant must stop as fast as possible by pressing any key. Worthy of note, the length of the task ( $\sim 33 \mathrm{~min})$ enables to analyze the decrement of both types of vigilance across the six blocks with sufficient precision, and adequate reliability for using the task in experimental designs (Luna, Roca, et al., 2020). 
Research on the ANTI-Vea has focused on providing empirical dissociation of and task sensitivity to both vigilance components. In this vein, EV decrement - but not AV-is mitigated by high-definition transcranial direct current stimulation over the right frontal and parietal cortices (Luna, Román-Caballero, et al., 2020) or acute moderate exercise (Sanchís et al., 2020), and modulated by the cognitive task load (Luna, 2019). Conversely, AV decrement—-but not EV — is reduced by acute caffeine intake (Sanchís et al., 2020) and increased with fatigue across $8 \mathrm{hr}$ of testing (Feltmate et al., 2019). Furthermore, the ANTI-Vea has been used to study individual differences related to musical (Román-Caballero et al., 2020) or sport (Huertas et al., 2019) practice as well as mindfulness and mind-wandering dispositions (Cásedas et al., 2020). No previous studies have employed this task in the field of ADHD.

\section{Measuring Distraction in ADHD: A Novel Paradigm}

Although distraction is central to ADHD symptomatology, evidence of increased distractor interference in ADHD is rather inconsistent (Albrecht et al., 2008; Brodeur \& Pond, 2001; Chan et al., 2009; Huang-Pollock et al., 2005; Lundervold et al., 2011; Mason et al., 2004; Wilding, 2005). Forster (2013) pointed out that this literature failed in the attempt to employ a paradigm with distractors that were entirely irrelevant to the task. For instance, in the responsecompetition paradigm (e.g., flanker tasks), although distractors appear in an irrelevant location where the target is never presented, their identity is highly relevant to the task, as it is associated with one of the target responses (i.e., congruent vs. incongruent). This does not reflect the type of distraction that people — most frequently those with ADHD — experience in daily life, where an entirely irrelevant distractor (e.g., a mobile notification) interferes with the ongoing task (e.g., reading a paper). 
Therefore, to measure task-irrelevant distraction, distractors must be presented in an irrelevant location, unrelated to any task responses, visually dissimilar from the search stimuli, and irrelevant to any attentional setting for the current task (Forster, 2013). In line with this, Forster and Lavie (2008) designed the irrelevant-distractor paradigm to measure the interference associated with the peripheral presentation of a colorful salient task-irrelevant distractor, typically a well-known character (e.g., Pikachu). Using this paradigm, irrelevant distraction was positively associated with ADHD in both case-control (Forster et al., 2014) and nonclinical correlational studies (Forster \& Lavie, 2016; but see Meier, 2020, for an unsuccessful replication). Crucially, Forster and Lavie (2016) found that while interference from irrelevant distractors correlated positively with ADHD symptoms, interference from response-competition distractors did not.

Since the ANTI-Vea measures interference by a response-competition paradigm (i.e., flanker task), it may be possible that integrating the irrelevant-distractor paradigm could enhance the task sensitivity to ADHD symptoms.

\section{The Present Study}

The aim of our study was to investigate the main attentional processes related to ADHD symptoms through a single, fine-grained task. For that purpose, we integrated the irrelevantdistractor paradigm into the ANTI-Vea. This allows to measure simultaneously attentional networks, vigilance, and distraction, three key domains in the study of attention and ADHD. To better characterize ADHD's nature, we employed a community sample of undergraduates, and both childhood and current symptoms were evaluated. Grounded on the aforementioned literature, we expected higher ADHD symptoms to predict: (a) poorer functioning in alerting and executive networks (i.e., higher effects), but not in orienting; (b) impoverished EV and AV- 
crucially in performance over time (i.e., vigilance decrement); and (c) higher irrelevantdistraction effect. In parallel, we intended to explore the sensitivity and feasibility of this modified ANTI-Vea version to reflect ADHD-related differences, facing more applied purposes.

\section{Method}

\section{Participants}

Following the reference work by Forster and Lavie (2016), we decided to collect data from 120 participants. This sample size allows to detect a small to medium effect size $(r=.22$; smaller than $r=.32$, observed by Forster and Lavie, 2016) in one-tailed, zero-order correlations with $1-\beta=.80$ and $\alpha=.05$, as computed with $G^{*}$ Power 3.1. Therefore, a sample of 120 undergraduates of Psychology, Speech Therapy, Sport Sciences, and Criminology from the University of Granada participated in the study. They received extra credit course as a compensation for their voluntary participation. All participants ( 95 women, 23 men; age, $M=$ $20.21, S D=1.91$, range 18-28) were Spanish-speaking and had a normal or corrected-to-normal vision. Only one participant reported a prior diagnosis of ADHD.

All participants completed an informed consent form. The study was conducted in accordance with the ethical guidelines laid down by the University of Granada, in compliance with the ethical standards of the 1964 Declaration of Helsinki, and was part of a larger research project (PSI2017-84926-P) approved by the University of Granada Ethical Committee (175/CEIH/2017).

\section{Instruments}

Barkley Adult ADHD Rating Scale-IV: Childhood and Current Symptoms 
The self-reports of the Barkley Adult ADHD Rating Scale-IV (BAARS-IV; Barkley, 2011) include two scales to asses ADHD symptoms ${ }^{1}$ : retrospectively in childhood (cBAARS-IV) and concurrently in adulthood (aBAARS-IV). Each scale is composed of 18 items, nine of inattention (e.g., "forgetful in daily activities) and nine of hyperactivity-impulsivity (e.g., "fidget with hands or feet or squirm in seat"), in a Likert scale ranged from 1 (never or rarely) to 4 (very often). Since the items are based on the Diagnostic and Statistical Manual of Mental Disorders (4th ed.; DSM-IV; APA, 1994), we used the Spanish version of the manual for the translation (APA, 1994/1995). In our sample, internal consistency was $\alpha=.89$ and $\alpha=.86$ for cBAARS-IV and aBAARS-IV, respectively, closed to the $\alpha=.95$ and $\alpha=.92$ of the original BAARS-IV (Barkley, 2011).

\section{Adult ADHD Self-Report Screening Scale for DSM-5}

The Adult ADHD Self-Report Screening Scale for DSM-5 (ASRS-5; Ustun et al., 2017) specifically assesses the adult presentation of ADHD based on DSM-5 conceptualization (APA, 2013). It includes six items (e.g., "how often do you put things off until the last minute") in a 5point Likert scale $(0=$ never to $4=$ very often $)$. The items were translated into Spanish based on previous Spanish versions of the ASRS (National Comorbidity Survey, n.d.), along with a Spanish portal of health sciences (Redacción Médica, n.d.). Internal consistency of ASRS-5 in our sample was $\alpha=.64$, which is within the range of the original study (Ustun et al., 2017).

\section{ANTI-Vea With Irrelevant Distractors}

The original ANTI-Vea (Luna et al., 2018; see online version on https://www.ugr.es/ neurocog/ANTI/), which evaluates the three attentional networks (ANTI

\footnotetext{
${ }^{1}$ We did not administer the subscales of Sluggish Cognitive Tempo included in the BAARS-IV.
} 
trials) and two types of vigilance (EV and AV trials), was modified in order to add the irrelevant distractor paradigm on the task (ID trials). This task includes a fixation cross $(\sim 7 \mathrm{px})$ in all trials. ANTI and EV trials include a warning tone $(2000 \mathrm{~Hz})$, an asterisk $(\sim 14 \mathrm{px})$, and five arrows (the central target plus four flankers; $\sim 50 \mathrm{px}$ width $\times \sim 23 \mathrm{px}$ height each). Arrows are horizontally separated by $\sim 63$ px from each other. To increase difficulty by generating noise, arrows are also randomly displaced $\pm 2 \mathrm{px}$ (both vertically and horizontally) from their position. Along with the random displacement, the central arrow is vertically displaced by 8 px in EV trials. Everything was used as in the original task, except that 8 ID trials were added to each bock of trials. These trials were built as ANTI trials, but with the replacement of nontarget arrows by lines, and the inclusion of a distractor (SpongeBob, Pikachu, or Mickey Mouse; 200 px width $\times \sim 200$ px height) located $\sim 150 \mathrm{px}$ or $\sim 290 \mathrm{px}$ above or below the central arrow. AV trials presented a red millisecond down counter ( $\sim 110$ px height each number).

\section{Procedure}

The study was conducted between November 2019 and March 2020—-before COVID-19 preventive measures being implemented in our region. First, participants filled out an online survey_via LimeSurvey (https://www.limesurvey.org)—composed by questionnaires about attention and distraction dispositions ${ }^{2}$. The survey began with the cBAARS-IV, the aBAARS-IV, and the ASRS-5, in that order; and ended with a question about previous diagnosis of ADHD. After completing the survey, participants were cited in our laboratory to conduct the cognitive task.

\footnotetext{
${ }^{2}$ The full set of questionnaires, which is part of a larger project, is available at a public repository (Coll-Martín et al., 2020).
} 
Upon arrival at the laboratory, participants were individually brought into a soundproof room adequately illuminated. Participants were sitting at about $60 \mathrm{~cm}$ from a 15 inches computer screen with an aspect ratio of 16:9. Participants were provided with headphones at $60 \%$ sound level of the computer and were asked to disconnect or silence their mobile phone. Then, the experimenter presented the ANTI-Vea, designed and run in E-Prime (Version 2.0; Psychology Software Tools, Inc, 2012). The stimuli sequence and correct responses for each type of trial are depicted in Figure 1. 


\section{Figure 1}

Attention Network Test for Interaction and Vigilance-Executive and Arousal Components (ANTI-Vea) Procedure in our Study

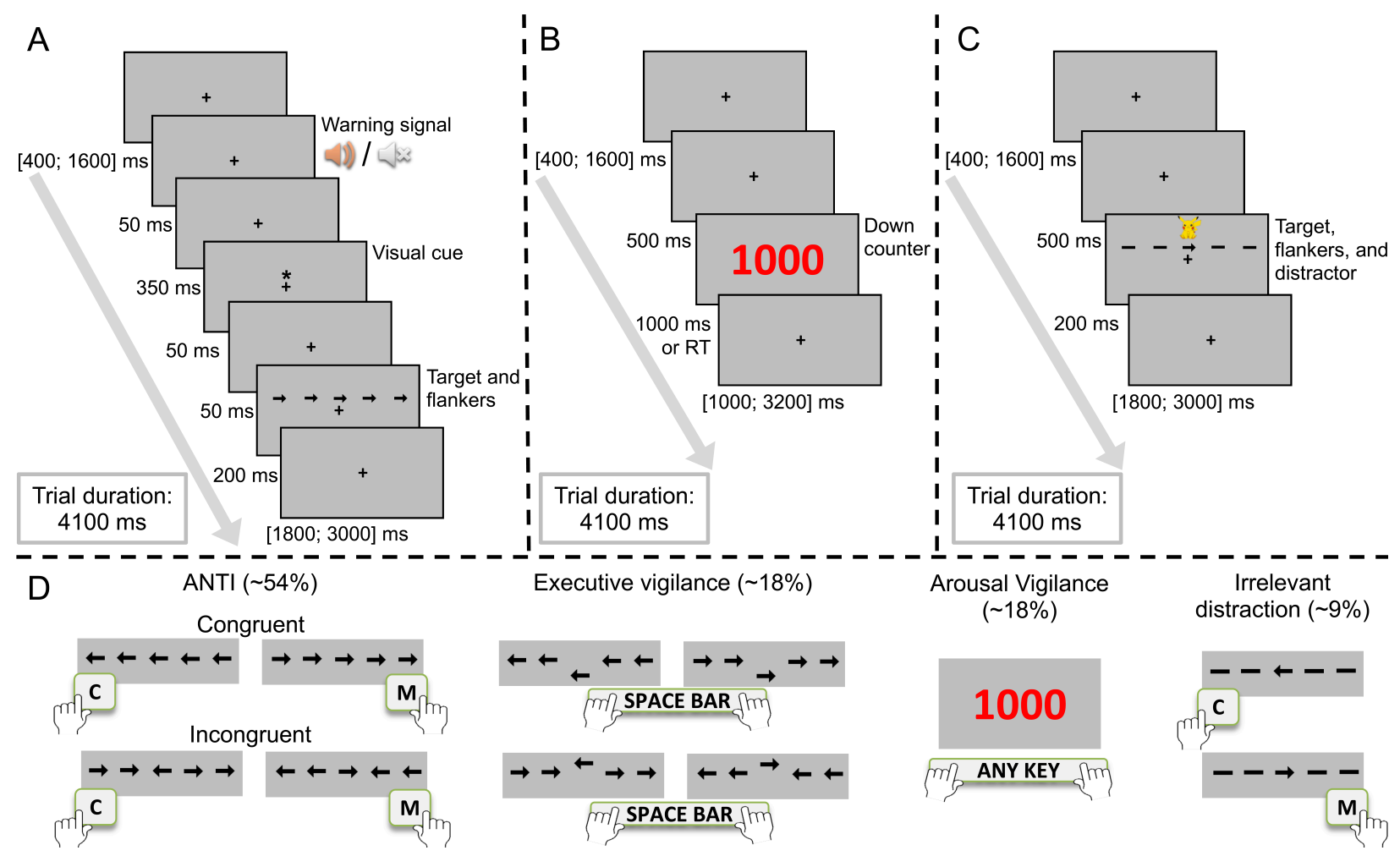

Note. Panel A: Temporal sequence in Attention Network Test for Interaction (ANTI) and Executive Vigilance (EV) trials. Target and flankers could appear above (see example) or below the fixation point. Visual cue could appear in the same location as the target (valid cue; see example), in the opposite location (invalid cue), or could not appear (no cue). Panel B: Temporal sequence in Arousal Vigilance (AV) trials. Panel C: Temporal sequence in Irrelevant distraction (ID) trials. Target and flankers could appear above (see example) or below the fixation point. Irrelevant distractor could appear at the top (see example) or at the bottom of the screen; or it could not appear. Distractor could be Pikachu (see example), SpongeBob, or Mickey Mouse. Panel D: Correct responses for each type of trial. The five arrows are randomly displaced $\pm 2 \mathrm{px}$ to generate noise in ANTI and ID trials, and the target is displaced by 8 px in EV trials. 
All the trials lasted $4100 \mathrm{~ms}$ and had a fixation point constantly present at the center of the screen. The ANTI-Vea comprised four different types of trials: the three from the original task (ANTI, EV, and AV) and one added to measure irrelevant distraction (ID). Trials were pseudorandomly presented within their experimental block. In ANTI ( $\sim 54 \%$; 48 trials per block) and EV trials $(\sim 18 \%$; 16 trials per block) an auditory warning signal sounded in half of the trials (tone condition), whereas in the other half no warning signal was presented (no tone condition). Next, an asterisk (i.e., visual spatial cue) appeared in two third of the trials. This cue could equally be presented in the same (valid condition) or the opposite (invalid condition) location as the oncoming target. Right after, a central arrow (i.e., target) with four flankers appeared either above or below the fixation point. In ANTI trials, participants had to discriminate the direction of the target (by pressing either "c" for leftward direction, or " $\mathrm{m}$ " for rightward direction) while ignoring the direction of the flanking arrows, which could equally point to the same (congruent condition) or the opposite (incongruent condition) as the target. In contrast, EV trials required participants to detect the large target vertical displacement by pressing the space bar while ignoring the direction of target and flankers. In contrast, AV trials $(\sim 18 \% ; 16$ trials per block) only displayed a red millisecond down counter that replaced the fixation point at the center of the screen at a variable time interval (900-2100 ms). Participants had to stop the down counter by pressing any key as fast as possible. Finally, ID trials $(\sim 9 \% ; 8$ trials per block) had the same structure and correct response as ANTI trials without tone or cue, except: (a) nontarget arrows were replaced by lines to reduce perceptual load, and (b) in half of the trials an irrelevant distractor (e.g., Pikachu) appeared either at the top or at the bottom of the screen for the same time as the target (distractor present condition), whereas no distractor was presented in the other half (distractor absent condition). 
The ANTI-Vea task started with a practice phase, as in Luna et al. (2018). In this phase, instructions about the four different type of trials were gradually described and interspersed with practice trials including visual feedback, in the following order: ANTI, EV, AV, and ID trials. Participants were encouraged to keep their eyes on the fixation point all the time and to respond as quickly and accurately as possible during the whole task. ID trials were directly included in a last practice block of 48 randomized trials (24 ANTI, $8 \mathrm{EV}, 8 \mathrm{AV}, 8 \mathrm{ID}$ ) without visual feedback. Before this practice block, the three type of distractors (SpongeBob, Pikachu, and Mickey Mouse) were shown to participants, who were told to "ignore them, as they were irrelevant to the task goal". After this block, participants were given the possibility to search for and ask any doubt to the experimenter, who had left the room at the beginning of the practice phase. Then, participants started the six seamless experimental blocks (48 ANTI, $16 \mathrm{EV}, 16 \mathrm{AV}$, 8 ID trials per block). The whole experimental session—instructions and task — lasted $\sim 50 \mathrm{~min}$.

\section{Data Analysis}

Behavioral data were treated based on Luna et al. (2018) through an R script. Because of a computer or experimenter error, ANTI-Vea data from three participants were corrupted and they could not be analyzed. Participants with more than $25 \%$ errors in ANTI trials $(n=4$, among them, the only participant with ADHD) were excluded from all task analyses, and those remaining participants with more than $25 \%$ errors in the distractor present condition $(n=11)$ were excluded from all ID trials analyses ${ }^{3}$. For ANTI and ID RT analyses, trials with incorrect

\footnotetext{
${ }^{3}$ This filter for (ID) trials was added in response to the first data analysis, due to the extremely high percentage errors of these participants in the distractor present condition $(M d n=.94)$. Most of them probably understood that "ignore the distractors" meant "do not response when the distractor appears".
} 
responses $(\mathrm{ANTI}=5.75 \%$; ID $=5.68 \%)$ and $\mathrm{RTs}$ smaller than $200 \mathrm{~ms}(\mathrm{ANTI}=1.24 \%$; ID $=$ $1.96 \%)$ or higher than $1500 \mathrm{~ms}(\mathrm{ANTI}=0.45 \%$; ID $=0.78 \%)$ were excluded.

We extracted several measures from the ANTI-Vea. For mean $R T$ and percentage errors in ANTI trials, we calculated the overall mean score and difference scores for alerting (no tone tone conditions ${ }^{4}$ ), orienting (invalid - valid conditions), and congruency (incongruent congruent conditions). EV outcomes included hits (percentage of correct responses in EV trials), false alarms (percentage of space bar responses in ANTI trials with more than $2 \mathrm{px}$ from the target to at least one of its two adjacent flankers; see Luna et al, in press), and the signal detection theory metrics of $A^{\prime}$ (sensitivity) and $B^{\prime \prime}$ (response bias). AV outcomes compressed the mean $R T$, the standard deviation $R T$, and the percentage of lapses (RTs $>600 \mathrm{~ms}$ ). Each EV and AV outcome included both the overall performance and the slope of the regression linerepresenting performance over the six experimental blocks. Finally, ID trials provided interference from irrelevant distractor. As per Forster and Lavie (2016), we computed the percentage increase in mean $R T$ due to distraction by dividing the difference score (distraction present - distractor absent conditions) by RT in the distractor absent conditions. Distraction interference in percentage errors only employed raw difference scores.

We analyzed the quality of the ANTI-Vea measures. First, we checked the task functioning. To this end, we conducted Student's t-tests for indexes based on difference scores. For indexes based on performance over experimental blocks (i.e., EV and AV slopes), we conducted six-level one way repeated-measures analyses of variance (ANOVAs) with planned comparisons to test the polynomial linear component. Where appropriate, Huynh-Feldt or

\footnotetext{
${ }^{4}$ Although the measure exclusively considering the no-cue conditions seems to be a purer measure of alertness (Callejas et al., 2004), the measure considering all conditions is more reliable.
} 
Greenhouse-Geisser corrections were applied. Second, we estimated the internal consistency reliability of each ANTI-Vea outcome. To do so, we used a permutation-based split-half correlation approach with 10,000 random splits and then applied the Spearman-Brown correction (for a rationale, see Parsons et al., 2019). These reliability estimations were computed by adapting an R script that had previously been used with the original ANTI-Vea (Luna, Roca, et al., 2020).

Finally, we used JASP (Version 0.13; JASP Team, 2020) to test the correlations between the three questionnaires of ADHD symptoms (i.e., cBAARS-IV, aBAARS-IV, and ASRS-5) and the 24 ANTI-Vea outcomes ( 8 ANTI, 8 EV, 6 AV, 2 ID). Normality was violated for the vast majority of pairwise comparisons, as assessed by Shapiro-Wilk tests. Therefore, we used the Kendall's $\tau$ rank correlation coefficient, interpreted as per Gilpin (1993): .07 = small, .21 = medium, .35 = large. We conducted one- or two-sided contrasts according to whether they were based on directional or nondirectional hypotheses. Statistical significance was set at $\alpha=.05$.

\section{Results}

\section{ADHD Self-Reports}

Unsurprisingly, the cBAARS-IV $(M=29.6, S D=8.46)$, the aBAARS-IV $(M=28.4, S D$ $=7.32)$, and the ASRS-5 $(M=8.04, S D=3.54)$ showed significant positive correlations among them, with effect sizes from medium to large. Concretely, for the cBAARS-IV with the aBAARS, $r(118)=.51, p<.001$, for the cBAARS-IV with the ASRS-5, $r(118)=.35, p<.001$, and for the aBAARS-IV with the ASRS-5, $r(118)=.70, p<.001$. Interestingly, the correlation between the two measures of symptoms in adulthood was higher than those between these measures and the one of symptoms in childhood. Correlation between these ADHD self-reports and ANTI-Vea outcomes are depicted in Table 1 and will be further analyzed below. 


\begin{abstract}
ANTI-Vea
Table 1 shows descriptive statistics, reliability, and correlations with ADHD symptoms for each of the ANTI-Vea indexes. Correlations among ANTI-Vea indexes are presented in Supplemental Table 1.
\end{abstract}

\title{
ANTI Outcomes
}

As reported by Luna et al., (2018), ANTI trials revealed effects of alerting, orienting and congruency for RTs and, except orienting, for percentage errors. Specifically, RTs were faster in the tone than in the no tone trials, $t(112)=-9.18, p<.001, d=-0.84$, in valid than invalid trials, $t(112)=-14.45, p<.001, d=-1.36$, and in congruent than incongruent trials, $t(112)=-14.80, p$ $<.001, d=-1.39$. Percentage errors were higher in no tone than in tone trials, $t(112)=6.54, p<$ $.001, d=0.62$, and in incongruent than congruent trials, $t(112)=3.69, p<.001, d=0.35$; the difference between invalid and valid trials only reached a nonsignificant trend, $t(112)=1.79, p=$ .08. Reliability of ANTI outcomes ranged from $r_{S B}=.26$ to $r_{S B}=.99$, with higher values for overall than for difference scores (see Table 1).

In line with our hypotheses, we observed significant positive correlations between the cBAARS-IV and the magnitude of the alerting effect (i.e., the difference between no tone and tone trials) in both $\mathrm{RTs}, \tau(111)=.13, p=.021$, and percentage errors, $\tau(111)=.15, p=.013$. For the aBAARS-IV, however, such correlations with alerting in $\mathrm{RTs}, \tau(111)=.10, p=.063$, and percentage errors, $\tau(111)=.09, p=.083$, turned into nonsignificant trends. The ASRS-5 did not correlate with RTs or percentage errors of alerting (both $p>.248$ ). Contrary to our predictions, none of the three ADHD self-reports significantly correlated with the overall scores of RT (all $p$ $>.193$ ) or percentage errors (all $p>.186$ ) nor with the congruency effect, either measured with RTs (all $p>.205$ ) or percentage errors (all $p>$.314). Finally, as expected, orienting indexes of 
RT (all but one $p>$.804) and percentage errors (all $p>$.494) did not correlate with any ADHD self-report. Only RT orienting exhibited a nonsignificant positive trend with the ASRS-5, $\tau(111)$ $=.11, p=.085$.

\section{EV Outcomes}

The four EV indexes of overall performance (i.e., hits, false alarms, $A^{\prime}$, and $B^{\prime \prime}$ ) yielded high reliability scores, from $r_{S B}=.85$ to $r_{S B}=.94$ (see Table 1). However, none of these indexes showed significant correlations with any of the three ADHD self-reports (all but one $p>.219$ ). Only the aBAARS-IV showed a nonsignificant negative trend of negative with $B^{\prime \prime}, \tau(111)=.11$, $p=.077$, indicating that higher scores in the aBAARS-IV predicted a more conservative response style to the target detection.

Consistently with Luna et al., (2018), we found a main effect of experimental block for hits, $F(5,560)=8.85, p<.001, \eta^{2}=.07$, false alarms, $F(4.51,505.16)=2.56, p<.032, \eta^{2}=.02$, and $B^{\prime \prime}, F(4.79,536.58)=4.13, p<.001, \eta^{2}=.04$. Planned comparisons revealed a linear component indicating that, over the six blocks, there were a decrement in the percentage of hits, $t(560)=-6.27, p<.001$, and false alarms, $t(112)=-2.94, p=.004$, as well as an increase in $B^{\prime \prime}$, $t(112)=4.01, p<.001$. Different from Luna et al., we also observed the block effect on $A^{\prime}$, $F(4.28,478.82)=2.91, p<.019, \eta^{2}=.03$, yielding a linear decrease over the blocks, $t(112)=-$ $3.13, p=.002$. These indexes of slope exhibited a low internal consistency, ranging from $r_{S B}=$ .26 to $r_{S B}=.40$.

Concerning our hypotheses, only the ASRS-5 correlated with two indexes of EV slopes. Specifically, higher ASRS-5 scores predicted a greater decrement in percentage of hits, $\tau(111)=$ $-.11, p=.044$, and $A^{\prime}$ (sensitivity), $\tau(111)=-.14, p=.017$, as well as a more attenuated decrement in percentage of false alarms, $\tau(111)=-.11, p=.044$. The aBAARS-IV yielded two 
nonsignificant trends of correlation with the slope of percentage of false alarms, $\tau(111)=-.09, p$ $=.085$, and the slope of $A^{\prime}, \tau(111)=-.09, p=.091$, both in the same direction as the ASRS-5. The remaining correlations were not significant (all $p>.494)$.

\section{AV Outcomes}

Similar to EV, we found high internal consistency for the three AV indexes of overall performance, oscillating between $r_{S B}=.88$ and $r_{S B}=.97$ (see Table 1). As predicted, the cBAARS-IV exhibited significant positive correlations with the three indexes, namely, mean RT, $\tau(111)=.11, p=.043$, standard deviation of the $\mathrm{RT}, \tau(111)=.11, p=.044$, and percentage of lapses, $\tau(111)=.11, p=.041$. Neither the aBAARS-IV nor the ASRS-5 significantly correlated with any AV index (all but one $p>$.108). Only the ASRS-5 showed a nonsignificant positive trend with mean $\mathrm{RT}, \tau(111)=.10, p=.061$.

In line with Luna et al., (2018), there was a main effect of experimental block for mean $\mathrm{RT}, F(3.94,441.51)=8.47, p<.001, \eta^{2}=.07$, standard deviation of the $\mathrm{RT}, F(4.18,468.41)=$ $7.46, p<.001, \eta^{2}=.06$, and percentage of lapses, $F(3.46,387.16)=14.38, p<.001, \eta^{2}=.11$. All these variables increased linearly across the blocks, namely, mean $\mathrm{RT}, t(112)=4.56, p<.001$, standard deviation of the RT, $t(112)=5.13, p=.001$, and percentage of lapses, $t(112)=5.68, p<$ .001 . Reliability for the three indexes of slope ranged from $r_{S B}=.54$ to $r_{S B}=.78$.

Like for AV overall performance, only the cBAARS-IV exhibited significant correlations with indexes of AV slopes, concretely, with the slope of mean $\mathrm{RT}, \tau(111)=.17, p=.004$, and the slope of percentage of lapses, $\tau(111)=.18, p=.002$; as well as a nonsignificant positive trend with the slope of standard deviation of the RT, $\tau(111)=.08, p=.099$. No significant correlations were found between the two other self-reports (i.e., the aBAARS-IV and the ASRS5) and the three measures of AV slope (all $p>.169$ ). 


\section{ID Outcomes}

In the same vein as Forster and Lavie (2016), participants were slower in the presence (M $=640.99, S D=103.59)$ versus in the absence $(M=608.92, S D=103.59)$ of the irrelevant distractor, $t(101)=7.14, p<.001, d=0.71$. Nevertheless, both conditions did not significantly differ in the percentage of errors, $t(101)=0.95, p=.342, d=0.09$. Internal consistency for indexes of percentage increase in mean RT $\left(r_{S B}=.21\right)$ and percentage errors $\left(r_{S B}=.03\right)$ were found to be low. Contrary to our predictions, none of the three self-reports correlated with either percentage increase in mean $\mathrm{RT}($ all $p>.310)$ or percentage errors (all $p>.240)$.

In order to examine the role of the distractor position in relation to the target, we conducted a further exploratory analysis. Distractor present trials were divided according to whether the distractor appeared on the same (as in Figure 1) or on the opposite side as the target (e.g., below fixation when the target appeared above). Compared to the condition without distractor, RTs were slower for both the distractor present same side condition, $M_{\Delta \mathrm{RT}}=36.12$, $S D_{\Delta \mathrm{RT}}=46.11, t(101)=7.91, p<.001, d=0.78$, and the distractor present opposite side condition, $M_{\Delta \mathrm{RT}}=27.88, S D_{\Delta \mathrm{RT}}=58.48, t(101)=4.82, p<.001, d=0.48$. There were no differences between the two distractor present conditions, $t(101)=1.56, p=.123, d=0.15$. While the effect of distraction (i.e., percentage increase in mean RT) from the opposite side did not correlate with any ADHD self-report (all $p>$.494), distraction-same effect showed a significant positive correlation with the ASRS-5, $\tau(100)=.12, p=.037$, but not with the cBAARS-IV or the aBAARS-IV (both $p>.172$ ). Nonetheless, the reliability estimate was low for distractor-same effect $\left(r_{S B}=.26\right)$ and virtually zero for distractor-opposite effect $\left(r_{S B}=-.08\right)$.

\section{Table 1}


Descriptive Statistics, Internal Consistency, and Kendall's Rank Correlations With ADHD

Symptoms in Childhood and Adulthood for all ANTI-Vea Outcomes

\begin{tabular}{|c|c|c|c|c|c|c|}
\hline \multirow[b]{2}{*}{ ANTI-Vea index } & \multirow[b]{2}{*}{$M$} & \multirow[b]{2}{*}{$S D$} & \multirow[b]{2}{*}{$r_{S B}$} & \multicolumn{3}{|c|}{ Kendall's $\tau$ correlation coefficient } \\
\hline & & & & cBAARS-IV & aBAARS-IV & ASRS-5 \\
\hline \multicolumn{7}{|l|}{ ANTI outcomes } \\
\hline RT overall & 600 & 95 & .99 & .06 & -.08 & -.03 \\
\hline$\%$ errors overall & 5.75 & 4.34 & .91 & .06 & -.08 & -.06 \\
\hline RT alerting & 20 & 23 & .47 & $.13^{*}$ & $.10^{\dagger}$ & .03 \\
\hline$\%$ errors alerting & 2.33 & 3.79 & .51 & $.15^{*}$ & $.09^{\dagger}$ & .05 \\
\hline RT orienting & 35 & 26 & .36 & .01 & .02 & $.11^{\dagger \dagger}$ \\
\hline$\%$ errors orienting & 0.65 & 3.90 & .26 & .04 & -.01 & -.05 \\
\hline RT congruency & 40 & 28 & .66 & .05 & .03 & .03 \\
\hline$\%$ errors congruency & 1.46 & 4.21 & .60 & .03 & .01 & -.06 \\
\hline \multicolumn{7}{|l|}{ EV outcomes } \\
\hline$\%$ hits & 68.62 & 17.29 & .94 & .001 & -.05 & .01 \\
\hline$\%$ false alarms & 5.16 & 5.09 & .85 & -.001 & -.11 & -.02 \\
\hline$A^{\prime}$ (sensitivity) & .90 & .04 & .88 & -.01 & -.02 & .02 \\
\hline$B^{\prime \prime}$ (response bias) & .59 & .35 & .86 & -.02 & $.11^{\dagger \dagger}$ & .02 \\
\hline$\%$ hits slope & -1.74 & 3.00 & .27 & -.02 & -.04 & $-.11^{*}$ \\
\hline$\%$ false alarms slope & -0.42 & 1.51 & .40 & .05 & $.09^{\dagger}$ & $.11^{*}$ \\
\hline$A^{\prime}$ (sensitivity) slope & -.003 & .01 & .40 & -.03 & $-.09^{\dagger}$ & $-.14^{*}$ \\
\hline$B^{\prime \prime}$ (response bias) slope & .04 & .10 & .26 & -.01 & -.11 & -.08 \\
\hline \multicolumn{7}{|l|}{ AV outcomes } \\
\hline RT mean & 504 & 58 & .97 & $.11^{*}$ & .04 & $.10^{\dagger}$ \\
\hline RT standard deviation & 97 & 49 & .88 & $.11^{*}$ & .06 & .01 \\
\hline$\%$ lapses & 12.98 & 14.35 & .96 & $.11^{*}$ & .07 & .08 \\
\hline RT mean slope & 5.36 & 12.47 & .75 & $.17^{* *}$ & .06 & -.01 \\
\hline RT SD slope & 6.10 & 12.62 & .54 & $.08^{\dagger}$ & .02 & -.05 \\
\hline \% lapses slope & 1.99 & 3.74 & .78 & $.18^{* *}$ & .06 & -.01 \\
\hline \multicolumn{7}{|l|}{ ID outcomes ${ }^{a^{a}}$} \\
\hline$\%$ interference in $\mathrm{RT}$ & 5.37 & 7.35 & .21 & .02 & .02 & .03 \\
\hline$\%$ errors interference & 0.61 & 6.49 & .03 & -.01 & .02 & .05 \\
\hline
\end{tabular}

Note. $n=113 . \mathrm{ADHD}=$ Attention-deficit/hyperactivity disorder. $r_{S B}=$ Spearman-Brown reliability coefficient. cBAARS-IV = Barkley Adult ADHD Rating Scale-IV: Childhood Symptoms. aBAARS-IV = Barkley Adult ADHD Rating Scale-IV: Current Symptoms. ASRS-5 $=$ Adult ADHD Self-Report Screening Scale for DSM-5. ANTI $=$ Attention Network Test for Interaction. $\mathrm{EV}=$ Executive vigilance. $\mathrm{AV}=$ Arousal Vigilance. $\mathrm{ID}=$ Irrelevant distraction. $\mathrm{RT}=$ Reaction time. According to our hypotheses, correlation tests are one-tailed for positive 
correlations in all indexes, except: (a) orienting (RT and errors; two-tailed); (b) hits and A' (both overall and slope; one-tailed for negative correlations); and (c) B" (only overall; two-tailed), as it is the only index not directionally associated with performance in vigilance.

${ }^{\mathrm{a}} n=102$.

${ }^{\dagger} p<.10$, one-tailed. ${ }^{\dagger \dagger} p<.10$, two-tailed. ${ }^{*} p<.05$, one-tailed. ${ }^{* *} p<.01$, one-tailed. No other $p<$ .05 appeared with exploratory two-tailed tests.

\section{Discussion}

This study aimed at analyzing the main attentional processes related to ADHD symptoms, namely, attentional networks, executive and arousal vigilance, and distraction. To do so, we modified a single, fine-grained task (i.e., the ANTI-Vea) to add a distraction component (Forster \& Lavie, 2016). Different from the bulk of the literature, we employed a community sample of undergraduates and measured retrospective and current ADHD symptoms. Although the ANTI-Vea worked successfully, the internal consistency was reduced for many indexes. We found a relation between ADHD symptoms and a higher alerting effect, but not orienting or congruency effects. ADHD also related to a poorer performance over time in EV and to alterations in different AV measures. No association was found between ADHD and irrelevant distraction. Worthy of note, our pattern of results was not consistent across the three ADHD selfreports or the specific task indexes. Therefore, our hypotheses were supported only partially at most. These findings have implications for ADHD pathophysiology and for the role of experimental tasks in the study of ADHD symptoms. 


\section{Attentional Networks}

In line with our hypothesis, the finding of a higher alerting effect associated with ADHD symptoms is consistent with Berger and Posner's (2000) predictions. It also fits the state regulation deficit account of ADHD (Sergeant, 2000, 2005; Sonuga-Barke et al., 2010). From this view, a task context such as the ANTI-Vea, which has been shown to be suitable to measure a vigilance decrement, would tend to induce underactivation. This state would be especially detrimental for tonic arousal and activation levels in those individuals with higher levels of ADHD symptoms. As a consequence, environmental stimulation, such as warning signals, would compensate for that underactivated state, thereby bringing performance to normal levels. Although impaired alerting network is well-established in ADHD children (Arora et al., 2020), this phenomenon has been less frequently reported in adults with ADHD (e.g., Oberlin et al., 2005). For instance, our findings are inconsistent with those reported by Lundervold et al. (2011), who found no difference in any attentional network between adults with ADHD and controls, despite we had similar statistical power and a more homogeneous sample than them (i.e., no participants with ADHD). Differences in the task length or difficulty, or in the type of warning signal (auditory vs. visual) could help explain these contradictory findings.

The lack of an association between ADHD and the orienting effect in our data is theoretically and empirically consistent with previous literature (Arora et al., 2020; Berger \& Posner, 2000; Huang-Pollock \& Nigg, 2003; Lundervold et al., 2011). Of note, most research uses the original ANT, which provides a global index of orienting network. However, tasks such as the ANTI or the ANTI-Vea specifically assesses exogenous orienting, which is related to automatic processes (Ishigami et al., 2016). The scarce research on exogenous orienting in 
ADHD has failed to find alterations in children (Casagrande et al., 2012; Mullane et al., 2011), which is consonant with our results in nonclinical adults.

Contrary to our hypothesis, we could not find an association between ADHD symptoms and the congruency effect. This is somehow surprising, as executive attention has been hypothesized to be deficient in ADHD (Berger \& Posner, 2000), and evidences using the ANT in children (Arora et al., 2020) and adults (Lampe et al., 2007; Oberlin et al., 2012; but see Lundervold et al., 2011) have supported this notion. Beyond the differences in sample size and composition between our study and previous literature, we believe that the difference between tasks is highly relevant in this regard. In the ANT and the ANTI, the flanker task is performed as a single task whose only goal is to respond to the target direction. By contrast, the ANTI-Vea incorporates a second goal into the mindset, which is simultaneous to the first one - namely, to respond to the vertical displacement of the target. This type of increase in the working memory load has been found to reduce the flanker interference, leading to a lower congruency effect (Luna, Telga, et al., 2020). Indeed, the congruency effect we obtained for RT and percentage errors were less than half of the usually reported in the ANT in nonclinical adults (MacLeod et al., 2010). This substantially lower congruency effect probably makes the index less sensitive to modulation from individual differences, such as ADHD symptoms, which is a concern about the ANTI-Vea to bear in mind. Alternatively, this result could be interpreted in the sense that ADHD adults, when appropriately challenged by task demands, as in the ANTI-Vea task, can overcome any putative executive deficit they might have.

\section{Executive and Arousal Vigilance}

Partial support for our hypothesis of a poorer EV associated to ADHD symptoms were limited to indexes of performance over time (i.e., vigilance decrement). This is rather the 
opposite pattern as Huang-Pollock et al.'s (2012) meta-analysis with children, who found larger ADHD deficits in overall performance than in performance over time. Performance over time is considered the appropriate form to measure vigilance (Huang-Pollock et al., 2012; Tucha et al., 2017). Nonetheless, numerous tasks used in ADHD research have failed to produce a main effect of vigilance (e.g., Johnson et al., 2001; Marchetta et al., 2008; Tucha et al., 2017). However, the ANTI-Vea task has been specifically developed to induce such vigilance decrement, one of the key characteristics in ADHD. Further research comparing clinical ADHD with nonclinical controls in the ANTI-Vea is likely to find larger and more consistent differences in vigilance decrement than previously reported.

Different from other EV tasks, vigilance decrement in the ANTI-Vea manifests as a change to a more conservative response criterion (i.e., increase in $B^{\prime \prime}$ ), rather than as a loss of sensitivity $\left(A^{\prime}\right)$ (Luna, Roca, et al., 2020). In spite of this, our data showed ADHD symptoms to be associated with a loss of sensitivity over the task, but not with a more conservative response style - indeed, we observed the opposite trend. This pattern, consistent with previous research (Huang-Pollock et al., 2012, 2020), suggest that the vigilance impairments in ADHD are more a matter of ability than of willingness (Thompson et al., 2016). However, the relatively low rate of false alarms in this literature, prevents us from ruling out a floor effect that might be overestimating the role of sensitivity at the expense of underestimating the role of response criterion.

Furthermore, we found ADHD symptoms - only retrospectively reported in childhoodto be associated with a diminished AV, in both mean RT and response variability (i.e., standard deviation and percentage of lapses). These results support our hypothesis and are consonant with the few studies comparing adults with ADHD in overall and over time AV measures of response 
variability (Gmehlin et al., 2016; Tucha et al., 2017). However, different from previous works, we did find a greater decrement of mean RT. As in the case of EV, the fact that the ANTI-Vea is the only task of this literature that generates decrement in AV might account for such discrepancies. Moreover, the higher response variability associated to ADHD that we found in AV seems to reflect the ubiquity and robustness of this phenomenon. That is, ADHD relates to variability of response in multiple types of tasks (Epstein et al., 2011; Kofler et al., 2013).

A theoretical issue that is also relevant to the study of ADHD is the type of relationship between EV and AV. Grounded on van Zomeren and Brouwer's (1994) attentional model, Gmehlin et al. (2016) argued that sustained alertness (strongly related to AV) is a precondition for more complex attentional functions overt time - this includes processes that could be considered as components of EV. According to this view, Gmehlin et al. found that, when controlling for the slope of AV (i.e., change in percentage of lapses across blocks), differences between ADHD and control groups in EV disappeared. By contrast, there is evidence supporting that EV and AV, albeit probably related, constitute independent components of vigilance (e.g., Luna et al., 2019; Luna, Román-Caballero, et al., 2020; Sanchís et al., 2020). In our data, using an equivalence test for correlations (Lakens et al., 2017), we found statistical support to reject a small or higher positive correlation $(r \geq .1)$ between the slopes of the percentages of hits $(\mathrm{EV})$ and lapses $(\mathrm{AV}), r(111)=-.06, p=.044$. This suggests that $\mathrm{EV}$ and $\mathrm{AV}$ does not depend on each other in a meaningful way. Furthermore, the partial correlation between ADHD symptoms (ASRS-5) and the slope of the percentage of hits, controlling for the percentage of lapses, remained significant, $\tau(110)=-.11, p=.037$. This result, inconsistent with Gmehlin et al., does not support the idea of $\mathrm{AV}$ as a prerequisite for $\mathrm{EV}$ and is in line with the notion of ADHD as a heterogeneous condition (Fair et al., 2012). 


\section{Irrelevant Distraction}

Although we found an acceptable effect of ID on the RT, the lack of correlation with ADHD symptoms does not support our hypothesis, and it is contrary to Sophie and Lavie's (2016) findings. In fact, our results are in line with the recent Meier's (2020) failed attempt to replicate Sophie and Lavie's results using exactly the same task and a similar sample composition (i.e., university students). Against the case of a Forster and Lavie's false positive, it should be noted that they also found a positive correlation in a second experiment with a different task as well as in a case-control study comparing ADHD with controls (Forster et al., 2014). Therefore, the possibility of a true effect is still likely. Regarding the event of a false negative in Meier's and our study, assuming the effect found by Forster and Lavie $(r=.32)$, a very high statistical power was achieved by Meier (.99) and us (.95). Moreover, Meier found Bayesian evidence favoring the null hypothesis. Of note, the reliability of the ID index reported by Meier and us was rather low $\left(r_{S B}=.26\right.$ and .21 , respectively). This importantly reduces the size of the observed correlation with ADHD symptoms, leading to the need of a higher sample size and reliability scores to reach the desired power (Parsons et al., 2019). Further studies are warranted not only to consistently determine the existence of a positive correlation between the ID effect and ADHD symptoms, but also to test whether this correlation is stronger than those using task-relevant distractors (e.g., flanker task). As our exploratory analysis showed, the distractor position might play an important role to replicate the correlation between ADHD symptoms and ID effect in the ANTI-Vea.

\section{Measuring ADHD Symptoms in Childhood and Adulthood}

To gain a better knowledge of ADHD, we used three different but complementary measures: one for symptoms in childhood (cBAARS-IV) and the other two for symptoms in 
adulthood (aBAARS-IV and ASRS-5). Characterizing developmental trajectories in ADHD is important to obtain more homogeneous subgroups and phenotypes, also at the neurocognitive level (Luo et al., 2019; Sonuga-Barke \& Halperin, 2010). In a longitudinal study, Moffit et al. (2015) found that ADHD in childhood had very little overlapping with the adult-onset form of ADHD. Moreover, at age 38, only participants with ADHD in childhood showed neuropsychological deficits, including overall performance in EV. Although EV was the only domain where we found poorer performance to be associated with ADHD symptoms in adulthood but not in childhood, our altered EV indexes were of performance over time. In fact, our general picture of results differentiated ADHD symptoms in childhood versus in adulthood. While the former predicted alterations in arousal (i.e., alerting network and AV), the latter were negatively associated with executive outcomes (i.e., EV decrement). This dissociation is, to some extent, consonant with Halperin and Schulz's (2006) neurodevelopmental model of ADHD. This model postulates that, while the early onset of the disorder is associated with subcortical structures involving arousal, the persistence of the ADHD in the adulthood is related to prefrontal regions which underlie executive processes. Although this is a tentative account, it has to be mentioned that another study with similar EV and AV measures have yielded a less developmentally dissociable pattern (Gmehlin et al., 2016).

Within ADHD symptoms in adults, it is noteworthy that, while the ASRS-5 yielded some significant correlations with ANTI-Vea measures, the aBAARS-IV did not. Besides the possible statistical errors that will be mentioned in the next section, a tentative account is related to the different form of both self-reports to measure adult ADHD symptoms. The aBAARS-IV uses the 18 DSM-IV criteria (without examples) as items. The content of these items is generic for children and adults. By contrast, the ASRS-5 is not only based on DSM-5 criteria, which better 
reflect the adult presentation, but also include items specifically designed to detect ADHD in adults (Ustun et al., 2017). Therefore, instead of a lack of relationship between adult ADHD symptoms and neuropsychological deficits, it might be that highly sensitive self-reports are needed to accurately capture the adult presentation of the disorder, along with its underlying alterations.

\section{Limitations}

We have identified two main caveats in our study. First, the general picture of correlations between attentional processes and ADHD self-reports shows that, at best, our hypotheses were supported only partially. That is, no attentional domain exhibited significant correlations with ADHD symptoms across the three self-reports. Also, for those observed significant correlations the effect sizes were at most small to medium. Although our study did not analyze people with ADHD, the quartiles of the scores in the cBAARS-IV and the aBAARSIV were similar to the ones obtained by Barkley (2011). Thus, there is no major reason to think that the level of ADHD symptoms in our sample is more homogeneous - and less sensitive to correlate with behavioral tasks - than in other nonclinical samples. A more plausible reason is related to the psychometric properties of the ANTI-Vea indexes. Although our task reliability scores are similar to the ones reported in Luna, Roca, et al. (2020), the internal consistency found for difference scores and slopes tended to be fairly low. This limitation, which is also inherent to most cognitive tasks (Dang et al., 2020; Hedge et al., 2018), could dramatically attenuate the observed correlations coefficients. Futures studies should either attempt to improve the reliability of their tasks or use valid methods to correct for low reliability to estimate the true correlation between ADHD symptoms and attentional processes. 
The second limitation concerns the control of the type I error rate in our results. Since our study did not reach a very high statistical power, strict corrections for multiple comparisons were likely to dramatically increase the rate of false negatives. Following McDonald's (2014) suggestion, we conducted an exploratory secondary analysis where we applied the BenjaminiHochberg procedure (Benjamini \& Hochberg, 1995) to our correlation matrix in order to control for a false discovery rate of $20 \%$. Groups for multiple comparisons were set according to our hypotheses. The significant findings of this corrected pattern of correlations are roughly similar to such comparisons before the correction (see Supplemental Table 2). In any case, to attain a more proper control of both types of statistical errors, our study needs to be replicated with a larger sample.

\section{Conclusion}

To conclude, our modified version of the ANTI-Vea was useful for measuring the functioning of the attentional networks, executive and arousal vigilance, and irrelevant distraction. This fine-grained distinction between attentional processes is relevant to gain a depth understanding of ADHD pathophysiology. In a sample of undergraduates, we found that ADHD symptoms in childhood were related to alerting and arousal processes while symptoms in adulthood were rather associated to the executive component of vigilance. Different from other neuropsychological tasks, the ANTI-Vea could successfully induce vigilance decrement. However, compared to other tasks (e.g., ANT), our index of the executive attentional network (i.e., congruency effect) was fairly reduced by task demands. Moreover, some of the task indexes (especially those involving difference scores) exhibited a poor internal consistency. Although replications with larger and clinical samples are necessary, this thorough approach to the 
attentional processes in ADHD might shed light on the search for more homogeneous subgroups of the disorder. 


\section{References}

Adólfsdóttir, S., Sørensen, L., \& Lundervold, A. J. (2008). The Attention Network test: A characteristic pattern of deficits in children with ADHD. Behavioral and Brain Functions, 4, Article 9. https://doi.org/10.1186/1744-9081-4-9

Advokat, C., Martino, L., Hill, B. D., \& Gouvier, W. (2007). Continuous Performance Test (CPT) of college students with ADHD, psychiatric disorders, cognitive deficits, or no diagnosis. Journal of Attention Disorders, 10(3), 253-256. https://doi.org/10.1177/1087054706292106

Albrecht, B., Brandeis, D., Uebel, H., Heinrich, H., Mueller, U. C., Hasselhorn, M., Steinhausen, H. C., Rothenberger, A., \& Banaschewski, T. (2008). Action monitoring in boys with attention-deficit/hyperactivity disorder, their nonaffected siblings, and normal control subjects: evidence for an endophenotype. Biological Psychiatry, 64(7), 615-625. https://doi.org/10.1016/j.biopsych.2007.12.016

American Psychiatric Association. (1994). Diagnostic and statistical manual of mental disorders (4th ed.).

American Psychiatric Association. (1995). Manual diagnóstico y estadístico de los transtornos mentales [Diagnostic and statistical manual of mental disorders] (J. J. López-Ibor Aliño, Dir.; M. Valdés Miyar, Coord.;4th ed.). Masson. (Original work published 1994) American Psychiatric Association. (2013). Diagnostic and statistical manual of mental disorders (5th ed.). https://doi.org/10.1176/appi. books.9780890425596

Arora, S., Lawrence, M. A., \& Klein, R. M. (2020). The Attention Network Test Database: ADHD and Cross-Cultural Applications. Frontiers in Psychology, 11, Article 388. https://doi.org/10.3389/fpsyg.2020.00388 
Barkley, R. A. (1997). Behavioral inhibition, sustained attention, and executive functions: Constructing a unifying theory of ADHD. Psychological Bulletin, 121(1), 65-94. https://doi.org/10.1037/0033-2909.121.1.65

Barkley, R. A. (2011). Barkley Adult ADHD Rating Scale-IV (BAARS-IV). Guilford Press.

Barkley, R. A., \& Murphy, K. R. (2011). The nature of executive function (EF) deficits in daily life activities in adults with ADHD and their relationship to performance on EF tests. Journal of Psychopathology and Behavioral Assessment, 33(2), 137-158. https://doi.org/10.1007/s10862-011-9217-x

Benjamini, Y., \& Hochberg, Y. (1995). Controlling the false discovery rate: A practical and powerful approach to multiple testing. Journal of the Royal Statistical Society: Series B (Methodological), 57(1), 289-300. http://www.jstor.org/stable/10.2307/2346101

Berger, A., \& Posner, M. I. (2000). Pathologies of brain attentional networks. Neuroscience \& Biobehavioral Reviews, 24(1), 3-5. https://doi.org/10.1016/S0149-7634(99)00046-9

Booth, J. E., Carlson, C. L., \& Tucker, D. M. (2007). Performance on a neurocognitive measure of alerting differentiates ADHD combined and inattentive subtypes: A preliminary report. Archives of Clinical Neuropsychology, 22, 423-432. https://doi.org/10.1016/j.acn.2007.01.017

Brodeur, D. A., \& Pond, M. (2001). The development of selective attention in children with attention deficit hyperactivity disorder. Journal of Abnormal Child Psychology, 29(3), 229-239. https://doi.org/10.1023/a:1010381731658

Bueno, V. F., Kozasa, E. H., da Silva, M. A., Alves, T. M., Louzã, M. R., \& Pompéia, S. (2015). Mindfulness meditation improves mood, quality of life, and attention in adults with 
attention deficit hyperactivity disorder. BioMed Research International, 2015, Article 962857. https://doi.org/10.1155/2015/962857

Bush, G. (2010). Attention-deficit/hyperactivity disorder and attention networks. Neuropsychopharmacology, 35(1), 278-300. https://doi.org/10.1038/npp.2009.120

Callejas, A. Lupiáñez, J. \& Tudela, P. (2004). The three attentional networks: On their independence and interactions. Brain and Cognition, 54, 225-227. https://doi.org/10.1016/j.bandc.2004.02.012

Casagrande, M., Martella, D., Ruggiero, M. C., Maccari, L., Paloscia, C., Rosa, C., \& Pasini, A. (2012). Assessing attentional systems in children with Attention Deficit Hyperactivity Disorder. Archives of Clinical Neuropsychology, 27(1), 30-44. https://doi.org/10.1093/arclin/acr085

Cásedas, L., Cebolla, A., \& Lupiáñez, J. (2020). Examining the link between dispositional mindfulness and multiple components of attention and vigilance [Manuscript in preparation]. Department of Experimental Psychology, University of Granada.

Castellanos, F. X., \& Tannock, R. (2002). Neuroscience of attention-deficit/hyperactivity disorder: The search for endophenotypes. Nature Reviews Neuroscience, 3(8), 617-628. https://doi.org/10.1038/nrn896

Chan, E., Mattingley, J. B., Huang-Pollock, C., English, T., Hester, R., Vance, A., \& Bellgrove, M. A. (2009). Abnormal spatial asymmetry of selective attention in ADHD. Journal of child Psychology and Psychiatry, and Allied Disciplines, 50(9), 1064-1072. https://doi.org/10.1111/j.1469-7610.2009.02096.x 
Cohen, A. L., \& Shapiro, S. K. (2007). Exploring the performance differences on the flicker task and the Conners' Continuous Performance Test in adults with ADHD. Journal of Attention Disorders, 11(1), 49-63. https://doi.org/10.1177/1087054706292162

Coll-Martín, T., Carretero-Dios, H., \& Lupiáñez, J. (2020). Attentional Networks, Vigilance, and Distraction in a Single Task (ANTI-Vea): Relations with ADHD Symptoms. Open Science Framework. http://osf.io/k8jdm

Conners, C.K. \& Multi-Health Systems Staff. (Eds.). (2000). Conners' Continuous Performance Test II: Computer program for Windows, technical guide, and software manual. MultiHealth Systems Inc.

Cortese, S. (2020). Pharmacologic Treatment of Attention Deficit-Hyperactivity Disorder. New England Journal of Medicine, 383(11), 1050-1056. https://doi.org/10.1056/NEJMra1917069

Dang, J., King, K. M., \& Inzlicht, M. (2020). Why are self-report and behavioral measures weakly correlated?. Trends in Cognitive Sciences, 24(4), 267-269. https://doi.org/10.1016/j.tics.2020.01.007

Dinges, D. F., \& Powell, J. W. (1985). Microcomputer analyses of performance on a portable, simple visual RT task during sustained operations. Behavior Research Methods, Instruments \& Computers, 17(6), 652-655. https://doi.org/10.3758/BF03200977

Engel G. L. (1977). The need for a new medical model: A challenge for biomedicine. Science, 196(4286), 129-136. https://doi.org/10.1126/science.847460

Epstein, J. N., Conners, C. K., Sitarenios, G., \& Erhardt, D. (1998). Continuous Performance Test results of adults with attention deficit hyperactivity disorder. Clinical Neuropsychologist, 12(2), 155-168. https://doi.org/10.1076/clin.12.2.155.2000 
Epstein, J. N., Johnson, D. E., Varia, I. M., \& Conners, C. K. (2001). Neuropsychological assessment of response inhibition in adults with ADHD. Journal of Clinical and Experimental Neuropsychology, 23(3), 362-371.

https://doi.org/10.1076/jcen.23.3.362.1186

Epstein, J. N., Langberg, J. M., Rosen, P. J., Graham, A., Narad, M. E., Antonini, T. N., Brinkman, W. B., Froehlich, T., Simon, J. O., \& Altaye, M. (2011). Evidence for higher reaction time variability for children with ADHD on a range of cognitive tasks including reward and event rate manipulations. Neuropsychology, 25(4), 427-441. https://doi.org/10.1037/a0022155

Eriksen, B. A., \& Eriksen, C. W. (1974). Effects of noise letters upon the identification of a target letter in a nonsearch task. Perception \& Psychophysics, 16(1), 143149. https://doi.org/10.3758/BF03203267

Esterman, M., \& Rothlein, D. (2019). Models of sustained attention. Current Opinion in Psychology, 29, 174-180. https://doi.org/10.1016/j.copsyc.2019.03.005

Evans, S. W., Owens, J. S., Wymbs, B. T., \& Ray, A. R. (2018). Evidence-based psychosocial treatments for children and adolescents with attention deficit/hyperactivity disorder. Journal of Clinical Child \& Adolescent Psychology, 47(2), 157-198. https://doi.org/10.1080/15374416.2017.1390757

Fair, D. A., Bathula, D., Nikolas, M. A., \& Nigg, J. T. (2012). Distinct neuropsychological subgroups in typically developing youth inform heterogeneity in children with ADHD. Proceedings of the National Academy of Sciences of the United States of America, 109(17), 6769-6774. https://doi.org/10.1073/pnas.1115365109 
Fan, J., McCandliss, B. D., Sommer, T., Raz, A., \& Posner, M. I. (2002). Testing the efficiency and independence of attentional networks. Journal of Cognitive Neuroscience, 14(3), 340-347. https://doi.org/10.1162/089892902317361886

Faraone, S. V., Asherson, P., Banaschewski, T., Biederman, J., Buitelaar, J. K., Ramos-Quiroga, J. A., Rohde, L. A., Sonuga-Barke, E. J., Tannock, R., \& Franke, B. (2015). Attentiondeficit/hyperactivity disorder. Nature Reviews Disease Primers, 1, Article 15020. https://doi.org/10.1038/nrdp.2015.20

Faraone, S. V., Biederman, J., \& Mick, E. (2006). The age-dependent decline of attention deficit hyperactivity disorder: A meta-analysis of follow-up studies. Psychological Medicine, 36(2), 159-165. https://doi.org/10.1017/S003329170500471X

Feltmate, B. B. T., Hurst, A., Kopf, M., Gagnon, F., \& Klein, R. M. (2019, November 14-17). On the potential for wearable technology in the modeling of vigilance and fatigue for aeronautic applications [Poster presentation]. 60th Annual Meeting of the Psychonomic Society, Montreal, QC, Canada.

Fletcher, J. M. (2014). The effects of childhood ADHD on adult labor market outcomes. Health Economics, 23(2), 159-181. https://doi.org/10.1002/hec.2907

Forster S. (2013). Distraction and mind-wandering under load. Frontiers in Psychology, 4, Article 283. https://doi.org/10.3389/fpsyg.2013.00283

Forster, S., \& Lavie, N. (2008). Failures to ignore entirely irrelevant distractors: The role of load. Journal of Experimental Psychology: Applied, 14(1), 73-83. https://doi.org/10.1037/1076-898X.14.1.73

Forster, S., \& Lavie, N. (2016). Establishing the Attention-Distractibility Trait. Psychological Science, 27(2), 203-212. https://doi.org/10.1177/0956797615617761 
Forster, S., Robertson, D. J., Jennings, A., Asherson, P., \& Lavie, N. (2014). Plugging the attention deficit: Perceptual load counters increased distraction in ADHD. Neuropsychology, 28(1), 91-97. https://doi.org/10.1037/neu0000020

Freire-Bueno, V. F., Kozasa, E. H., da Silva, M. A., Alves, T. M., Louzã, M. R., \& Pompéia, S. (2015). Mindfulness meditation improves mood, quality of life, and attention in adults with attention deficit hyperactivity disorder. BioMed Research International, 2015, Article, 962857. https://doi.org/10.1155/2015/962857

Gilpin, A. R. (1993). Table for conversion of Kendall's Tau to Spearman's Rho within the context of measures of magnitude of effect for meta-analysis. Educational and Psychological Measurement, 53(1), 87-

92. https://doi.org/10.1177/0013164493053001007

Gmehlin, D., Fuermaier, A. B., Walther, S., Tucha, L., Koerts, J., Lange, K. W., Tucha, O., Weisbrod, M., \& Aschenbrenner, S. (2016). Attentional lapses of adults with attention deficit hyperactivity disorder in tasks of sustained attention. Archives of Clinical Neuropsychology, 31(4), 343-357. https://doi.org/10.1093/arclin/acw016

Greenberg, L. M., \& Waldman, I. D. (1993). Developmental normative data on the Test of Variables of Attention (T.O.V.A.). Child Psychology \& Psychiatry \& Allied Disciplines, 34(6), 1019-1030. https://doi.org/10.1111/j.1469-7610.1993.tb01105.x

Halperin, J. M., \& Schulz, K. P. (2006). Revisiting the role of the prefrontal cortex in the pathophysiology of attention-deficit/hyperactivity disorder. Psychological Bulletin, 132(4), 560-581. https://doi.org/10.1037/0033-2909.132.4.560

Haslam, N., Williams, B., Prior, M., Haslam, R., Graetz, B., \& Sawyer, M. (2006). The latent structure of attention-deficit/hyperactivity disorder: A taxometric analysis. The 
Australian and New Zealand Journal of Psychiatry, 40(8), 639-647. https://doi.org/10.1080/j.1440-1614.2006.01863.x

Hasler, R., Perroud, N., Meziane, H. B., Herrmann, F., Prada, P., Giannakopoulos, P., \& Deiber, M. P. (2016). Attention-related EEG markers in adult ADHD. Neuropsychologia, 87, 120-133. https://doi.org/10.1016/j.neuropsychologia.2016.05.008

Hedge, C., Powell, G., \& Sumner, P. (2018). The reliability paradox: Why robust cognitive tasks do not produce reliable individual differences. Behavior Research Methods, 50(3), 11661186. https://doi.org/10.3758/s13428-017-0935-1

Hommel, B., Chapman, C. S., Cisek, P., Neyedli, H. F., Song, J. H., \& Welsh, T. N. (2019). No one knows what attention is. Attention, Perception, and Psychophysics, 81(7), 22882303. https://doi.org/10.3758/s13414-019-01846-w

Huang-Pollock, C. L., Karalunas, S. L., Tam, H., \& Moore, A. N. (2012). Evaluating vigilance deficits in ADHD: A meta-analysis of CPT performance. Journal of Abnormal Psychology, 121(2), 360-371. https://doi.org/10.1037/a0027205

Huang-Pollock, C. L., \& Nigg, J. T. (2003). Searching for the attention deficit in attention deficit hyperactivity disorder: The case of visuospatial orienting. Clinical Psychology Review, 23(6), 801-830. https://doi.org/10.1016/S0272-7358(03)00073-4

Huang-Pollock, C. L., Nigg, J. T., \& Carr, T. H. (2005). Deficient attention is hard to find: Applying the perceptual load model of selective attention to attention deficit hyperactivity disorder subtypes. Journal of Child Psychology and Psychiatry, 46(11), 1211-1218. https://doi.org/10.1111/j.1469-7610.2005.00410.x

Huang-Pollock, C., Ratcliff, R., McKoon, G., Roule, A., Warner, T., Feldman, J., \& Wise, S. (2020). A diffusion model analysis of sustained attention in children with attention deficit 
hyperactivity disorder. Neuropsychology, 34(6), 641-653.

https://doi.org/10.1037/neu0000636

Huertas, F., Ballester, R., Gines, H. J., Hamidi, A. K., Moratal, C., \& Lupiáñez, J. (2019).

Relative age effect in the sport environment. Role of physical fitness and cognitive function in youth soccer players. International Journal of Environmental Research and Public Health, 16(16), 1-19. https://doi.org/10.3390/ijerph16162837

Ishigami, Y., Eskes, G. A., Tyndall, A. V., Longman, R. S., Drogos, L. L., \& Poulin, M. J. (2016). The Attention Network Test-Interaction (ANT-I): Reliability and validity in healthy older adults. Experimental Brain Research, 234(3), 815-827. https://doi.org/10.1007/s00221-015-4493-4

JASP Team (2020). JASP (Version 0.13) [Computer software]. https://jasp-stats.org/

Johnson, D. E., Epstein, J. N., Waid, L. R., Latham, P. K., Voronin, K. E., \& Anton, R. F. (2001). Neuropsychological performance deficits in adults with attention deficit/hyperactivity disorder. Archives of Clinical Neuropsychology, 16(6), 587-604. https://doi.org/10.1093/arclin/16.6.587

Kofler, M. J., Rapport, M. D., Sarver, D. E., Raiker, J. S., Orban, S. A., Friedman, L. M., \& Kolomeyer, E. G. (2013). Reaction time variability in ADHD: A meta-analytic review of 319 studies. Clinical Psychology Review, 33(6), 795-811. https://doi.org/10.1016/j.cpr.2013.06.001

Lakens D. (2017). Equivalence Tests: A practical primer for $t$ tests, correlations, and metaanalyses. Social Psychological and Personality Science, 8(4), 355-362. https://doi.org/10.1177/1948550617697177 
Lampe, K., Konrad, K., Kroener, S., Fast, K., Kunert, H. J., \& Herpertz, S. C. (2007).

Neuropsychological and behavioural disinhibition in adult ADHD compared to borderline personality disorder. Psychological Medicine, 37(12), 1717-1729. https://doi.org/10.1017/S0033291707000517

Langner, R., \& Eickhoff, S. B. (2013). Sustaining attention to simple tasks: A meta-analytic review of the neural mechanisms of vigilant attention. Psychological Bulletin, 139(4), 870-900. https://doi.org/10.1037/a0030694

Loe, I. M., \& Feldman, H. M. (2007). Academic and educational outcomes of children with ADHD. Ambulatory Pediatrics, 7(1 Suppl.), 82-90. https://doi.org/10.1016/j.ambp.2006.05.005

Luna. F. G. (2019). Redes atencionales y vigilancia ejecutiva y de activación [Attentional networks and excutive and arousal vigilance] [Doctoral dissertation, University of Granada]. Digibug. http://hdl.handle.net/10481/56866

Luna, F. G., Barttfeld, P., Martín-Arévalo, E., \& Lupiáñez, J. (in press). The ANTI-Vea task: Analyzing the executive and arousal vigilance decrements while measuring the three attentional networks. Psicológica.

Luna, F. G., Marino, J., Roca, J., \& Lupiáñez, J. (2018). Executive and arousal vigilance decrement in the context of the attentional networks: The ANTI-Vea task. Journal of Neuroscience Methods, 306, 77-87. https://doi.org/10.1016/j.jneumeth.2018.05.011

Luna, F. G., Roca, J., Martín-Arévalo, E., \& Lupiáñez, J. (2020). Measuring Attention and Vigilance in the Laboratory vs. Online: The Split-half Reliability of the ANTI-Vea. Behavior Research Methods. https://doi.org/10.3758/s13428-020-01483-4 
Luna, F. G., Román-Caballero, R., Barttfeld, P., Lupiáñez, J., \& Martín-Arévalo, E. (2020). A High-Definition tDCS and EEG study on attention and vigilance: Brain stimulation mitigates the executive but not the arousal vigilance decrement. Neuropsychologia, 142, Article 107447. https://doi.org/10.1016/j.neuropsychologia.2020.107447

Luna, F. G., Telga, M., Vadillo, M. A., \& Lupiáñez, J. (2020). Concurrent working memory load may increase or reduce cognitive interference depending on the attentional set. Journal of Experimental Psychology: Human Perception and Performance, 46(7), 667680. https://doi.org/10.1037/xhp0000740

Lundervold, A. J., Adolfsdottir, S., Halleland, H., Halmøy, A., Plessen, K., \& Haavik, J. (2011). Attention Network Test in adults with ADHD-the impact of affective fluctuations. Behavioral and Brain Functions, 7(1), Article 27. https://doi.org/10.1186/1744-9081-7-27

Luo, Y., Weibman, D., Halperin, J. M., \& Li, X. (2019). A review of heterogeneity in attention deficit/hyperactivity disorder (ADHD). Frontiers in Human Neuroscience, 13, Article 42. https://doi.org/10.3389/fnhum.2019.00042

MacLeod, J. W., Lawrence, M. A., McConnell, M. M., Eskes, G. A., Klein, R. M., \& Shore, D. I. (2010). Appraising the ANT: Psychometric and theoretical considerations of the Attention Network Test. Neuropsychology, 24(5), 637651. https://doi.org/10.1037/a0019803

Marchetta, N. D., Hurks, P. P., De Sonneville, L. M., Krabbendam, L., \& Jolles, J. (2008). Sustained and focused attention deficits in adult ADHD. Journal of Attention Disorders, 11(6), 664-676. https://doi.org/10.1177/1087054707305108 
Marcus, D. K., \& Barry, T. D. (2011). Does attention-deficit/hyperactivity disorder have a dimensional latent structure? A taxometric analysis. Journal of Abnormal Psychology, 120(2), 427-442. https://doi.org/10.1037/a0021405

Martella, D., Aldunate, N., Fuentes, L. J., \& Sánchez-Pérez, N. (2020). Arousal and Executive Alterations in Attention Deficit Hyperactivity Disorder (ADHD). Frontiers in Pyschology, 11, Article 1991. https://doi.org/10.3389/fpsyg.2020.01991

Mary, A., Slama, H., Mousty, P., Massat, I., Capiau, T., Drabs, V., \& Peigneux, P. (2016). Executive and attentional contributions to Theory of Mind deficit in attention deficit/hyperactivity disorder (ADHD). Child Neuropsychology, 22(3), 345-365. https://doi.org/10.1080/09297049.2015.1012491

Mason, D. J., Humphreys, G. W., \& Kent, L. (2004). Visual search, singleton capture, and the control of attentional set in ADHD. Cognitive Neuropsychology, 21(6), 661-687. https://doi.org/10.1080/02643290342000267

McDonald, J. H. (2014). Handbook of biological statistics. Sparky House Publishing. http://www.biostathandbook.com/HandbookBioStatThird.pdf

Meier. M. E. (2020). Testing the attention-distractibility trait. PsyArXiv. https://doi.org/10.31234/osf.io/a4cjk

Moffitt, T. E., Houts, R., Asherson, P., Belsky, D. W., Corcoran, D. L., Hammerle, M., Harrington, H., Hogan, S., Meier, M. H., Polanczyk, G. V., Poulton, R., Ramrakha, S., Sugden, K., Williams, B., Rohde, L. A., \& Caspi, A. (2015). Is adult ADHD a childhoodonset neurodevelopmental disorder? Evidence from a four-decade longitudinal cohort study. The American Journal of Psychiatry, 172(10), 967-977. https://doi.org/10.1176/appi.ajp.2015.14101266 
Mullane, J. C., Corkum, P. V., Klein, R. M., McLaughlin, E. N., \& Lawrence, M. A. (2011). Alerting, orienting, and executive attention in children with ADHD. Journal of Attention Disorders, 15(4), 310-320. https://doi.org/10.1177/1087054710366384

National Comorbidity Survey. (n.d.). Adult ADHD Self-Report Scales (ASRS). https://www.hcp.med.harvard.edu/ncs/asrs.php

Nikolas, M. A., Marshall, P., \& Hoelzle, J. B. (2019). The role of neurocognitive tests in the assessment of adult attention-deficit/hyperactivity disorder. Psychological Assessment, 31(5), 685-698. https://doi.org/10.1037/pas0000688

Oberlin, B. G., Alford, J. L., \& Marrocco, R. T. (2005). Normal attention orienting but abnormal stimulus alerting and conflict effect in combined subtype of ADHD. Behavioural Brain Research, 165(1), 1-11. https://doi.org/10.1016/j.bbr.2005.06.041

Oken, B. S., Salinsky, M. C., \& Elsas, S. M. (2006). Vigilance, alertness, or sustained attention: Physiological basis and measurement. Clinical Neurophysiology, 117(9), 1885-1901. https://doi.org/10.1016/j.clinph.2006.01.017

Parsons, S., Kruijt, A.-W., \& Fox, E. (2019). Psychological science needs a standard practice of reporting the reliability of cognitive-behavioral measurements. Advances in Methods and Practices in Psychological Science, 2(4), 378-

395. https://doi.org/10.1177/2515245919879695

Petersen, S. E., \& Posner, M. I. (2012). The attention system of the human brain: 20 years after. Annual Review of Neuroscience, 35, 73-89. https://doi.org/10.1146/annurev-neuro$\underline{062111-150525}$

Polanczyk, G., de Lima, M. S., Horta, B. L., Biederman, J., \& Rohde, L. A. (2007). The worldwide prevalence of ADHD: A systematic review and metaregression analysis. The 
American Journal of Psychiatry, 164(6), 942-948.

https://doi.org/10.1176/ajp.2007.164.6.942

Posner, J., Polanczyk, G., \& Sonuga-Barke, E. J. S. (2020). Attention-deficit hyperactivity disorder. Lancet, 395(10222), 450-462. https://doi.org/10.1016/S0140-6736(19)33004-1

Posner, M. I. (1980). Orienting of attention. Quarterly Journal of Experimental Psychology, 32(1), 3-25. https://doi.org/10.1080/00335558008248231

Posner, M. I., \& Petersen, S. E. (1990). The attention system of the human brain. Annual Review of Neuroscience, 13(1), 25-42. https://doi.org/10.1146/annurev.ne.13.030190.000325

Psychology Software Tools, Inc. (2012). E-Prime (Version 2.0) [Computer Software]. https://pstnet.com/products/e-prime-legacy-versions/

Redacción Médica. (n.d.). Un cuestionario de 6 preguntas detecta el TDAH en adultos [A sixitems questionnaire detect ADHD in adults]. https://www.redaccionmedica.com/secciones/psiquiatria/un-cuestionario-de-6-preguntasdetecta-el-tdah-en-adultos-1647

Riccio, C. A., \& Reynolds, C. R. (2001). Continuous performance tests are sensitive to ADHD in adults but lack specificity: A review and critique for differential diagnosis. In J. Wasserstein, L. E. Wolf, \& F. F. LeFever (Eds.), Annals of the New York Academy of Sciences: Vol. 931. Adult attention deficit disorder: Brain mechanisms and life outcomes (p. 113-139). New York Academy of Sciences.

Richards L. M. (2013). It is time for a more integrated bio-psycho-social approach to ADHD. Clinical Child Psychology and Psychiatry, 18(4), 483-503. https://doi.org/10.1177/1359104512458228 
Roca, J., Castro, C., López-Ramón, M. F., \& Lupiáñez, J. (2011). Measuring vigilance while assessing the functioning of the three attentional networks: The ANTI-Vigilance task. Journal of Neuroscience Methods, 198(2), 312-324. https://doi.org/10.1016/j.jneumeth.2011.04.014

Román-Caballero, R., Martín-Arévalo, E., \& Lupiáñez, J. (2020). Attentional networks functioning and vigilance in expert musicians and non-musicians. Psychological research. Advance online publication. https://doi.org/10.1007/s00426-020-01323-2

Rosvold, H. E., Mirsky, A. F., Sarason, I., Bransome, E. D., Jr., \& Beck, L. H. (1956). A continuous performance test of brain damage. Journal of Consulting Psychology, 20(5), 343-350. https://doi.org/10.1037/h0043220

Rueda, M. R., Fan, J., McCandliss, B. D., Halparin, J. D., Gruber, D. B., Lercari, L. P., \& Posner, M. I. (2004). Development of attentional networks in childhood. Neuropsychologia, 42(8), 1029-1040. https://doi.org/10.1016/j.neuropsychologia.2003.12.012

Sanchís, C., Blasco, E., Luna, F. G., \& Lupiáñez, J. (2020). Effects of caffeine intake and exercise intensity on executive and arousal vigilance. Scientific Reports, 10, Article 8393. https://doi.org/10.1038/s41598-020-65197-5

Salomone, S., Fleming, G. R., Bramham, J., O'Connell, R. G., \& Robertson, I. H. (2020). Neuropsychological deficits in adult ADHD: Evidence for differential attentional impairments, deficient executive functions, and high self-reported functional impairments. Journal of Attention Disorders, 24(10), 1413-1424. https://doi.org/10.1177/1087054715623045 
Schoechlin, C., \& Engel, R. R. (2005). Neuropsychological performance in adult attention-deficit hyperactivity disorder: Meta-analysis of empirical data. Archives of Clinical Neuropsychology, 20(6), 727-744. https://doi.org/10.1016/j.acn.2005.04.005

Sergeant, J. (2000). The cognitive-energetic model: An empirical approach to attention-deficit hyperactivity disorder. Neuroscience \& Biobehavioral Reviews, 24(1), 7-12. https://doi.org/10.1016/s0149-7634(99)00060-3

Sergeant, J. A. (2005). Modeling attention-deficit/hyperactivity disorder: A critical appraisal of the cognitive-energetic model. Biological Psychiatry, 57(11), 1248-1255. https://doi.org/10.1016/j.biopsych.2004.09.010

Simon, V., Czobor, P., Bálint, S., Mészáros, A., \& Bitter, I. (2009). Prevalence and correlates of adult attention-deficit hyperactivity disorder: Meta-analysis. The British Journal of Psychiatry, 194(3), 204-211. https://doi.org/10.1192/bjp.bp.107.048827

Singh I. (2008). Beyond polemics: Science and ethics of ADHD. Nature Reviews. Neuroscience, 9(12), 957-964. https://doi.org/10.1038/nrn2514

Solanto, M. V., Etefia, K., \& Marks, D. J. (2004). The utility of self-report measures and the continuous performance test in the diagnosis of ADHD in adults. CNS Spectrums, 9(9), 649-659. https://doi.org/10.1017/s1092852900001929

Sonuga-Barke, E. J. S. (2013). Attention-deficit/hyperactivity disorder: Toward a developmental synthesis. In P. D. Zelazo, (Ed.), Oxford handbook of developmental psychology (Vol. 2, pp. 549-578). Oxford University Press. 
Sonuga-Barke, E. J. S. (2019, September 24). What causes ADHD? Can science improve treatment? [PowerPoint slides]. The Association for Child and Adolscent Mental Health. https://www.acamh.org/app/uploads/2010/09/Edmund-slides-sept-2019.pdf

Sonuga-Barke, E. J. S., \& Fearon, R. P. (2019). Commentary: 'Ready or not here I come': Developmental immaturity as a driver of impairment and referral in young-for-schoolgrade ADHD children. A reformulation inspired by Whitely et al.(2019). Journal of Child Psychology and Psychiatry, 60(4), 392-394. https://doi.org/10.1111/jcpp.13039

Sonuga-Barke, E. J. S., \& Halperin, J. M. (2010). Developmental phenotypes and causal pathways in attention deficit/hyperactivity disorder: Potential targets for early intervention? Journal of Child Psychology and Psychiatry, 51(4), 368-389. https://doi.org/10.1111/j.1469-7610.2009.02195.x

Sonuga-Barke, E. J., Wiersema, J. R., van der Meere, J. J., \& Roeyers, H. (2010). Contextdependent dynamic processes in attention deficit/hyperactivity disorder: Differentiating common and unique effects of state regulation deficits and delay aversion. Neuropsychology Review, 20(1), 86-102. https://doi.org/10.1007/s11065-0099115-0

Sturm, W., de Simone, A., Krause, B. J., Specht, K., Hesselmann, V., Radermacher, I., Herzog, H., Tellmann, L., Müller-Gärtner, H. W., \& Willmes, K. (1999). Functional anatomy of intrinsic alertness: Evidence for a fronto-parietal-thalamic-brainstem network in the right hemisphere. Neuropsychologia, 37(7), 797-805. https://doi.org/10.1016/s00283932(98)00141-9 
Thapar A. (2018). Discoveries on the genetics of ADHD in the 21st century: New findings and their implications. The American Journal of Psychiatry, 175(10), 943-950. https://doi.org/10.1176/appi.ajp.2018.18040383

Thomson, D. R., Besner, D., \& Smilek, D. (2016). A critical examination of the evidence for sensitivity loss in modern vigilance tasks. Psychological Review, 123(1), 7083. https://doi.org/10.1037/rev0000021

Tucha, L., Fuermaier, A. B., Koerts, J., Buggenthin, R., Aschenbrenner, S., Weisbrod, M., Thome, J., Lange, K. W., \& Tucha, O. (2017). Sustained attention in adult ADHD: Timeon-task effects of various measures of attention. Journal of Neural Transmission, 124(1), 39-53. https://doi.org/10.1007/s00702-015-1426-0

Tucha, L., Tucha, O., Laufkötter, R., Walitza, S., Klein, H. E., \& Lange, K. W. (2008). Neuropsychological assessment of attention in adults with different subtypes of attentiondeficit/hyperactivity disorder. Journal of Neural Transmission, 115(2), 269-278. https://doi.org/10.1007/s00702-007-0836-z

Tucha, L., Tucha, O., Walitza, S., Sontag, T. A., Laufkötter, R., Linder, M., \& Lange, K. W. (2009). Vigilance and sustained attention in children and adults with ADHD. Journal of Attention Disorders, 12(5), 410-421. https://doi.org/10.1177/1087054708315065

Tucha, O., Walitza, S., Mecklinger, L., Sontag, T. A., Kübber, S., Linder, M., \& Lange, K. W. (2006). Attentional functioning in children with ADHD - predominantly hyperactiveimpulsive type and children with ADHD - combined type. Journal of Neural Transmission, 113(12), 1943-1953. https://doi.org/10.1007/s00702-006-0496-4

Ustun, B., Adler, L. A., Rudin, C., Faraone, S. V., Spencer, T. J., Berglund, P., Gruber, M. J., \& Kessler, R. C. (2017). The World Health Organization Adult Attention- 
Deficit/Hyperactivity Disorder Self-Report Screening Scale for DSM-5. JAMA Psychiatry, 74(5), 520-527. https://doi.org/10.1001/jamapsychiatry.2017.0298

van Zomeren, A. H., \& Brouwer, W. H. (1994). Clinical neuropsychology of attention. Oxford University Press.

Vázquez-Marrufo, M., García-Valdecasas Colell, M., Galvao-Carmona, A., Sarrias-Arrabal, E., \& Tirapu-Ustárroz, J. (2019). El Attention Network Test en el estudio de los déficits cognitivos de pacientes con trastorno por déficit de atención [The Attention Network Test in the study of cognitive impairment of ADHD patients]. Revista de Neurología, 69(10), 423-432. https://doi.org/10.33588/rn.6910.2019202

Weyandt, L. L., Oster, D. R., Gudmundsdottir, B. G., DuPaul, G. J., \& Anastopoulos, A. D. (2017). Neuropsychological functioning in college students with and without ADHD. Neuropsychology, 31(2), 160-172. https://doi.org/10.1037/neu0000326

Wilding, J. (2005). Is attention impaired in ADHD? British Journal of Developmental Psychology, 23(4), 487-505. https://doi.org/10.1348/026151005X48972

Willcutt, E. G., Doyle, A. E., Nigg, J. T., Faraone, S. V., \& Pennington, B. F. (2005). Validity of the executive function theory of attention-deficit/hyperactivity disorder: A meta-analytic review. Biological Psychiatry, 57(11), 1336-1346.

https://doi.org/10.1016/j.biopsych.2005.02.006 